\title{
Acalculous cholecystitis occurring in the context of Plasmodium malariae infection: a case report
}

\author{
Eleanor F Harris*, Eugenie Younger and Meirion B Llewelyn
}

\begin{abstract}
Introduction: Acalculous cholecystitis has been shown to occur in the context of malarial infection with Plasmodium vivax and Plasmodium falciparum and requires prompt diagnosis and treatment to prevent complications. To the best of our knowledge this is the first reported case of the disease occurring in a patient infected with Plasmodium malariae.

Case presentation: We report the first case of acalculous cholecystitis associated with Plasmodium malariae in a 59-year-old male Nepalese ex-Gurkha soldier. He presented with fever and vomiting and later developed right upper quadrant pain. Abdominal ultrasound and computed tomography scans confirmed acalculous cholecystitis for which he was treated medically with chloroquine, gentamicin and metronidazole. He made a full recovery.

Conclusions: Physicians should be aware that in addition to Plasmodium vivax and Plasmodium falciparum infections, acalculous cholecystitis can occur in the context of Plasmodium malariae infection. Mechanisms for this are discussed but further studies are needed to establish the etiology of this association.
\end{abstract}

Keywords: Acalculous cholecystitis, Malaria, Plasmodium malariae

\section{Introduction}

Acalculous cholecystitis (or acute acalculous cholecystitis; AAC) is a condition characterized by gallbladder inflammation without gallstones, usually diagnosed by ultrasound. It is most commonly attributed to severe physiological insult such as sepsis, burns or trauma [1] but there have been several reports linking the disease with malaria infection [2,3]. Of the five Plasmodium parasites responsible for the disease in humans (Plasmodium falciparum, Plasmodium vivax, Plasmodium malariae, Plasmodium ovale and Plasmodium knowlesi), only $P$. falciparum and $P$. vivax have so far been associated with AAC. We report the first case of AAC occurring in the context of $P$. malariae infection.

\section{Case presentation}

A 59-year-old male Nepalese ex-Gurkha soldier currently working in Ghana was admitted with a 3-day history of malaise, fever, rigors and vomiting. He had returned from a trip to Nepal 3 weeks previously. He had a history of two previous malarial infections; the last

\footnotetext{
*Correspondence: elliefharris@gmail.com

Department of Infectious Diseases, Department of Medicine, Royal Gwent Hospital, Newport, Wales NP20 2UB, United Kingdom
}

occurring 1 year prior to admission. He had never used malarial prophylaxis. The only other significant medical history was of gout.

On admission he was alert and orientated, had a temperature of $38.3^{\circ} \mathrm{C}$, pulse 70 beats/minute and blood pressure of $106 / 64 \mathrm{mmHg}$. His physical examination was otherwise unremarkable. Laboratory studies showed a white blood cell count of $7.4 \times 10^{9} / \mathrm{L}$, hemoglobin $13.6 \mathrm{~g} / \mathrm{dL}$ and platelets $94 \times 10^{9} / \mathrm{L}$ (normal: 150 to $400 \times 10^{9} / \mathrm{L}$ ). Total bilirubin was $50 \mu \mathrm{mol} / \mathrm{L}$ ( 1 to $21 \mu \mathrm{mol} / \mathrm{L}$ ) and conjugated bilirubin $16 \mu \mathrm{mol} / \mathrm{L}$ ( 0 to $7 \mu \mathrm{mol} / \mathrm{L}$ ). Alanine transaminase (ALT) was $63 \mathrm{U} / \mathrm{L}$ (0 to 59U/L) and alkaline phosphatase (ALP) 118U/L.

An examination of the blood film showed that malarial parasites were present and subsequently confirmed by the London School of Tropical Medicine as Plasmodium malariae. He was therefore treated with oral chloroquine in line with the Health Protection Agency policy. A day after admission he developed generalized abdominal pain, followed in 24 hours by right upper quadrant (RUQ) pain. At this stage he had a persistent fever and laboratory studies demonstrated a rising C-reactive protein and deranged liver function tests. The peak value of 
ALP was $185 \mathrm{U} / \mathrm{L}$ (30 to $130 \mathrm{U} / \mathrm{L}$ ) and ALT $103 \mathrm{U} / \mathrm{L}$ (0 to $59 \mathrm{U} / \mathrm{L})$.

Abdominal computed tomography (CT) showed thickening of the gallbladder wall with surrounding fluid suspicious of cholecystitis. An ultrasound examination also showed gallbladder thickening $(>3.5 \mathrm{~mm})$ and pericholecystic fluid, thus fulfilling the necessary criteria needed for a diagnosis of acalculous cholecystitis [4] (Table 1). Mild splenomegaly was also noted on ultrasound. There was no evidence of gallstones. The surgical team was involved and because the liver function tests were only mildly deranged and there was no radiological evidence of duct dilatation, further imaging was deemed unnecessary.

Antibiotic treatment with gentamicin and metronidazole was commenced and over the next 3 days his fever resolved and liver function tests returned to normal. Repeat blood film showed no evidence of malarial parasites. His symptoms had completely resolved by day 11 and he was discharged home. On review in clinic 6 weeks later he had made a full recovery.

\section{Discussion}

Since the first reported case in 1999 [5] there have been 25 reported cases of AAC occurring in the context of malaria: 19 associated with $P$. falciparum infections; three associated with $P$. vivax (two in adults and one in a child), two cases involving a mixed infection with $P$. vivax and $P$. falciparum and our case associated with $P$. malariae infection as detailed above.

A recent review of 16 of these cases compared the presentation and clinical course of the illness across the cases [2]. Our case seems to correspond well with the clinical presentation of AAC in $P$. falciparum and $P$. vivax infections, namely nausea, vomiting and abdominal pain in association with mildly deranged liver function tests. Fever and moderate hypotension were also present in our case and these were common in other reported cases. As in the present case, RUQ abdominal pain was reported an average of 1 to 3 days after presentation.

Table 1 Ultrasonography criteria for acute acalculous cholecystitis

\begin{tabular}{ll}
\hline Major criteria & Minor criteria \\
\hline - Gallbladder wall thickening $\geq 3 \mathrm{~mm}$ & - Gallbladder distension ( $>5 \mathrm{~cm})$ \\
- Wall edema & - Echogenic bile (sludge) \\
- Mucosal sloughing & \\
- Pericholecystic fluid & \\
- Sonographic Murphy's sign
\end{tabular}

Two major or one major and two minor criteria are needed for diagnosis.
The majority of the cases were diagnosed using ultrasound, although two also used hepatobiliary iminodiacetic acid (HIDA) scans [2]. Ultrasound is generally accepted as the best first line investigation of AAC due to availability and portability [6]. A recent review reported sensitivities and specificities for AAC diagnosis of up to $92 \%$ and $100 \%$ respectively, although there is a large amount of variance between studies [6]. CT has a similar accuracy to ultrasound and is useful when an alternative diagnosis is being considered [4]. HIDA scans, although accurate in detecting calculous cholecystitis, have been shown to have a sensitivity as low as $68 \%$ in the case of acalculous cholecystitis [7].

With regard to disease course, the relatively fast resolution of symptoms with medical management as described above was also seen in most of the other cases $[2,3]$. The recommended treatment of AAC is broad spectrum antibiotics to cover enterococci and Gramnegative bacilli [1]. This is followed by percutaneous cholecystostomy if medical management is unsuccessful and severe cases may require cholecystectomy [1]. Only five of the 25 total cases involved surgical management (in the form of percutaneous cholecystostomy) and these were all in severe cases of malaria, four with $P$. falciparum infections $[3,8,9]$ and one with $P$. vivax [2]. Prompt diagnosis and treatment is important because delay can lead to gallbladder perforation or gangrene [1]. All cases of AAC reported with malaria infection had good outcomes however, with no deaths or significant residual morbidity reported.

The mechanisms underlying the occurrence of AAC in malaria infections are largely unknown with three main mechanisms being considered at present:

1. Ischemia

Oxygen-demand-related ischemia and subsequent reperfusion injury to the gallbladder are thought to be important factors in the development of AAC because the disease is seen in a number of low flow states and during critical illnesses such as in burns and septic shock [1]. Malaria can cause these low flow states due to severe hypotension and severe illness, in addition to hemolytic anemias which have been suggested as contributory factors [2]. However, only three of the reported cases of malaria-associated AAC described severe malaria $[2,9,10]$, whereas most, as in the case of $P$. malariae above, were relatively mild malarial infections and thus do not strongly support the ischemia mechanism. It has been suggested that a combination of mild hypoperfusion and hemolytic anemia may contribute to oxygen-demand ischemia but this remains to be proved [2]. 


\section{Cytokines}

Another proposed mechanism to explain AAC associated with malaria infections is the imbalance of anti-inflammatory and pro-inflammatory cytokines which can occur during malarial infections. Cytokines such as interleukin (IL)-6, IL-10, IL-12 and tumor necrosis factor-alpha are known to be induced during $P$. vivax and $P$. falciparum infections $[11,12]$ and may therefore create systemic inflammatory responses which can cause gallbladder injury. There are few studies of P. malariae pathogenesis, however, and the cytokine effects are unknown, although this remains a possibility for further study.

3. Sequestration A third mechanism for the pathogenesis of AAC in malaria is the phenomenon of sequestration. This has been well described in P. falciparum infections and is the process whereby a protein specific to P. falciparum causes protrusions called "knobs" to form on infected erythrocytes which then adhere to vessel walls and each other. This results in widespread vascular sludging and ischemia [2]. This could then lead to AAC due to gallbladder ischemia.

However, this elegant explanation cannot apply in the same way to $P$. vivax or $P$. malariae infections because they have not been shown to produce this protein or cause sequestration in the same way $[13,14]$. Nonetheless, $P$. vivax has been shown to induce erythrocyte binding using endothelial receptors in a similar manner to $P$. falciparum [13] and thus this may still be a potential explanation for AAC in P. vivax infections. With regard to our case, no erythrocyte binding has been shown in $P$. malariae infections although a recent atomic force microscope image of an erythrocyte infected with P. malariae has revealed a high density of "spiky excrescences" on its surface [15]. Their function remains unknown at present and further research is needed before this can be suggested as a possible mechanism for AAC in this case.

These three mechanisms all offer plausible explanations for malaria-related AAC in specific circumstances, but none offer an overall convincing etiology which explains the situation seen with different plasmodium species and differing severities of malarial infection. Interestingly, one recent paper has suggested that AAC can occur as an idiopathic phenomenon in young healthy individuals raising the possibility that malaria and AAC are in fact unrelated events. However, the study was small (11 patients with AAC) and was a retrospective study looking at patients who had cholecystectomy for their AAC [16]. This is in contrast to the cohort of patients with $\mathrm{AAC}$ in the context of malaria infection because they were mainly treated medically. Nonetheless this is an important area to consider and needs further investigation.

\section{Conclusions}

In addition to $P$. falciparum and $P$. vivax infection, AAC should be also considered a complication of $P$. malariae infection. The mechanisms underlying this are unclear and require further study. Clinical features and management are comparable to those in $P$. falciparum and $P$. vivax infections. In any case of malaria, regardless of the species involved, deranged liver function tests and RUQ pain should prompt investigations to exclude AAC in order to allow timely treatment if required.

\section{Consent}

Written informed consent was obtained from the patient for publication of this case report. A copy of the written consent is available for review by the Editor-in-Chief of this journal.

\section{Competing interests \\ The authors declare that they have no competing interests.}

\section{Authors' contributions}

$\mathrm{EH}$ and EY collected the case report data, analyzed the case and drafted the case report section. EH was the major contributor in writing the manuscript. ML was the consultant responsible for the care of the patient and provided the initial concept for the case report, as well as assistance in editing. All authors read and approved the final manuscript.

\section{Acknowledgements}

Many thanks to the patient for allowing us to publish his case.

Received: 19 March 2013 Accepted: 11 June 2013

Published: 26 July 2013

\section{References}

1. Barie PS, Eachempati SR: Acute acalculous cholecystitis. Curr Gastroenterol Rep 2003, 5(4):302-309

2. Curley JM, Mody RM, Gasser RA Jr: Malaria caused by Plasmodium vivax complicated by acalculous cholecystitis. Am J Trop Med Hyg 2011, 85(1):42-49.

3. Abreu C, Santos L, Poínhos R, Sarmento A: Acute acalculous cholecystitis in malaria: a review of seven cases from an adult cohort. Infection 2013. Epub ahead of print

4. Barie PS, Eachempati SR: Acute acalculous cholecystitis. Gastroenterol Clin North Am 2010, 39:343-357.

5. Dylewski JS, Al-Azragi T: Acalculous cholecystitis associated with Plasmodium falciparum infection. Clin Infect Dis 1999, 29(4):947-948.

6. Huffman $\mathrm{J}$, Schenker S: Acalculous cholecystitis: a review. Clin Gastroenterol Hepatol 2010, 8(1):15-22.

7. Ziessmann HA: Nuclear medicine hepatobiliary imaging. Clin Gastroenterol Hepatol 2010, 8(2):111-116.

8. Azevedo C, Coelho R, Ferreira A, Figueiredo P, Santos L, Sarmento A: Acute acalculous cholecystitis in a patient with severe malaria. Acta Med Port 2011, 24(3):631-634

9. Gaüzère BA, Roblin X, Blanc P, Xavierson G, Paganin F: Importation of Plasmodium falciparum malaria, in Réunion Island, from 1993 to 1996: epidemiology and clinical aspects of severe forms. Bull Soc Pathol Exot 1998, 91:95-98.

10. Maggi P, Coppola SL, Lamargese V, Lisco A, Tramacere F, Pastore G: Acute acalculous cholecystitis associated with co-infection by Plasmodium falciparum and Plasmodium vivax. J Infect 2002, 44:136-137. 
11. Day NP, Hien TT, Schollaardt T, Loc PP, Chuong LV, Chau TT, Mai NT, Phu NH, Sinh DX, White NJ, Ho M: The prognostic and pathophysiologic role of pro and anti-inflammatory cytokines in severe malaria. $J$ Infect Dis 1999, 180:1288-1297.

12. Andrade BB, Reis-Filho A, Souza-Neto SM, Clarêncio J, Camargo LM, Barral A, Barral-Netto M: Severe Plasmodium vivax malaria exhibits marked inflammatory imbalance. Malar J 2010, 9:13.

13. Carvalho BO, Lopes SC, Nogueira PA, Orlandi PP, Bargieri DY, Blanco YC, Mamoni R, Leite JA, Rodrigues MM, Soares IS, Oliveira TR, Wunderlich G, Lacerda MV, del Portillo HA, Araújo MO, Russell B, Suwanarusk R, Snounou G, Rénia L, Costa FT: On the cytoadhesion of Plasmodium vivax - infected erythrocytes. J Infect Dis 2010, 202:638-647.

14. Collins WE, Jeffery GM: Plasmodium malariae: parasite and disease. Clin Microbiol Rev 2007, 20(4):579-592.

15. Li A, Russell B, Renia L, Lek-Uthai U, Nosten F, Lim CT: High density of 'spiky' excrescences covering the surface of an erythrocyte infected with Plasmodium malariae. Br J Haematol 2010, 151(1):1.

16. Ganpathi IS, Diddapur RK, Eugene H, Karim M: Acute acalculous cholecystitis: challenging the myths. HPB (Oxford) 2007, 9:131-134.

doi:10.1186/1752-1947-7-197

Cite this article as: Harris et al:: Acalculous cholecystitis occurring in the context of Plasmodium malariae infection: a case report. Journal of Medical Case Reports 2013 7:197.

\section{Submit your next manuscript to BioMed Central and take full advantage of:}

- Convenient online submission

- Thorough peer review

- No space constraints or color figure charges

- Immediate publication on acceptance

- Inclusion in PubMed, CAS, Scopus and Google Scholar

- Research which is freely available for redistribution 